\title{
Glial Control of Endocannabinoid Heterosynaptic Modulation in Hypothalamic Magnocellular Neuroendocrine Cells
}

\author{
Shi Di, ${ }^{1}$ Ion R. Popescu, ${ }^{1}$ and Jeffrey G. Tasker ${ }^{1,2}$ \\ ${ }^{1}$ Department of Cell and Molecular Biology, and ${ }^{2}$ Neuroscience Program, Tulane University, New Orleans, Louisiana 70118
}

Cannabinoid receptors are functionally operant at both glutamate and GABA synapses on hypothalamic magnocellular neuroendocrine cells; however, retrograde endocannabinoid actions are evoked at only glutamate synapses. We tested whether the functional targeting of evoked retrograde endocannabinoid actions to glutamate, and not GABA, synapses on magnocellular neurons is the result of the spatial restriction of extracellular endocannabinoids by astrocytes. Whole-cell GABA synaptic currents were recorded in magnocellular neurons in rat hypothalamic slices following manipulations to reduce glial buffering of extracellular signals. Depolarization- and glucocorticoidevoked retrograde endocannabinoid suppression of synaptic GABA release was not detected under normal conditions, but occurred in both oxytocin and vasopressin neurons under conditions of attenuated glial coverage and depressed glial metabolic function, suggesting an emergent endocannabinoid modulation of GABA synapses with the loss of astrocyte function. Tonic endocannabinoid suppression of GABA release was insensitive to glial manipulation. Blocking cannabinoid transport mimicked, and increasing the extracellular viscosity reversed, the effect of suppressed glial buffering on the endocannabinoid modulation of GABA release. Evoked, but not tonic, endocannabinoid modulation of GABA synapses was mediated by 2-arachidonoylglycerol. Therefore, depolarization- and glucocorticoid-evoked 2-arachidonoylglycerol release from magnocellular neurons is spatially restricted to glutamate synapses by astrocytes, but spills over onto GABA synapses under conditions of reduced astrocyte buffering; tonic endocannabinoid modulation of GABA release, in contrast, is likely mediated by anandamide and is insensitive to astrocytic buffering. Astrocytes, therefore, provide dynamic control of stimulusevoked 2-arachidonoylglycerol, but not tonic anandamide, regulation of GABA synaptic inputs to magnocellular neuroendocrine cells under different physiological conditions.

\section{Introduction}

The two main endocannabinoids 2-arachidonoylglycerol (2-AG) and anandamide bind to presynaptic type I cannabinoid (CB1) receptors and play an important role in the modulation of synaptic transmission throughout the CNS. 2-AG is synthesized by the enzyme sn-1-specific diacylglycerol lipase (DGL) and released in an activity- and/or G-protein-coupled receptordependent manner to suppress neurotransmitter release (Wilson and Nicoll, 2002; Freund et al., 2003; McDonald et al., 2008; Heifets and Castillo, 2009). Whereas little is known about the anatomical localization of anandamide synthesis in the brain, the spatial arrangement of DGL and CB1 receptors at excitatory and inhibitory synapses differs across brain regions, suggesting that 2-AG signaling may vary from structure to structure and from synapse to synapse in the brain (Katona et al., 2006; Yoshida et al.,

\footnotetext{
Received June 21, 2012; revised 0ct. 11, 2013; accepted 0ct. 11, 2013.

Author contributions: S.D. and J.G.T. designed research; S.D. and I.R.P. performed research; S.D. analyzed data; S.D., I.R.P., and J.G.T. wrote the paper.

This work was supported by NIH Grant MH066958, by the Catherine and Hunter Pierson Chair in Neuroscience, and by the Tulane Research Enhancement Fund. We thank Katalin Halmos for her expert technical assistance in these studies.

Correspondence should be addressed to either Jeffrey Tasker or Shi Di, Department of Cell and Molecular Biology, Tulane University, 2000 Percival Stern Hall, New Orleans, LA 70118, E-mail: tasker@tulane.edu or sdi@tulane.edu. DOI:10.1523/JNEUROSCI.2971-12.2013

Copyright $\odot 2013$ the authors $\quad 0270-6474 / 13 / 3318331-12 \$ 15.00 / 0$
}

2011). Ultrastructural localization of DGL suggests that 2-AG is produced primarily at excitatory synapses in the hippocampus (Katona et al., 2006) and somatosensory cortex (Dudok et al., 2012); however, CB1 receptor expression is generally higher at inhibitory synapses in these regions (Katona and Freund, 2012), which suggests a higher sensitivity to endocannabinoid signaling distal to the source of endocannabinoid synthesis. The specificity and efficiency of retrograde endocannabinoid signaling, therefore, depends on both the presynaptic expression of $\mathrm{CB} 1$ receptors and the relative proximity of the postsynaptic endocannabinoid synthetic machinery.

In hypothalamic magnocellular neuroendocrine cells, depolarization and glucocorticoids evoke a retrograde endocannabinoid suppression of glutamate, and not GABA, inputs, despite the expression of functional $\mathrm{CB} 1$ receptors at both glutamate and GABA synapses (Di et al., 2005b, 2009). Glucocorticoids also modulate the GABA synaptic inputs to magnocellular neuroendocrine cells, although this is mediated by the retrograde release of nitric oxide, and not endocannabinoid, and causes a facilitation, rather than a suppression, of GABA release (Di et al., 2009). Thus, stimulated retrograde endocannabinoids target glutamate synapses on magnocellular neuroendocrine cells, and do not act on neighboring GABA synapses under normal conditions.

Astrocytes control extracellular neurotransmitter levels by forming a physical diffusion barrier and by mediating transmitter 
uptake (Piet et al., 2004; Gordon et al., 2009; Tasker et al., 2012). Astrocytic buffering of neurotransmitters depends on the coverage and physical isolation of synapses by astrocytic processes, as decreasing glial coverage of neurons increases synaptic crosstalk (Piet et al., 2004). The magnocellular neuroendocrine system of the supraoptic nucleus (SON) and paraventricular nucleus $(\mathrm{PVN})$ undergoes extensive neuronal-glial remodeling in response to physiological stimulation, such as chronic dehydration and lactation (Miyata et al., 1994; Theodosis and Poulain, 1999), which causes an increase in the extracellular concentrations of neurotransmitters (Oliet et al., 2001) and heterosynaptic spillover of neurotransmitters onto neighboring synapses (Piet et al., 2004). Here, we tested the hypothesis that the lack of effect of evoked endocannabinoid release on GABA synapses is the result of the buffering of extracellular endocannabinoids by astrocytes using whole-cell recordings of synaptic currents in magnocellular neurons in hypothalamic slices following manipulations that reduce glial buffering of extracellular messengers.

\section{Materials and Methods}

Animals. Male Sprague Dawley rats (4-6 weeks old, Charles River) were used in these experiments according to protocols approved by the Tulane University Institutional Animal Care and Use Committee. In some experiments, transgenic rats that express a vasopressin-enhanced green fluorescent protein fusion gene (VP-GFP; Haam et al., 2012) or an oxytocin-monomeric red fluorescent protein 1 fusion gene (OT-RFP) were used. The transgenic rat colonies were established from founders graciously provided by Dr. Yoichi Ueta of the University of Occupational and Environmental Health in Kitakyushu, Japan (Ueta et al., 2005; Katoh et al., 2011). Chronically dehydrated rats were given $2 \%$ saline in their drinking water and fed with dry pellet food ad libitum for 5-7 d. Control rats were age matched and housed under identical conditions except that they were provided with tap drinking water.

Slice preparation. Hypothalamic slices containing the SON were prepared as described previously (Di et al., 2003) with minor modifications. Briefly, rats were decapitated under isoflurane anesthesia, the brain was rapidly removed, and two to three coronal hypothalamic slices $(300 \mu \mathrm{m})$ containing the SON were sectioned. The slices were bisected along the midline (i.e., at the third ventricle) in an ice-cold, HEPES-buffered artificial CSF (aCSF) in which $\mathrm{NaCl}$ was replaced with an equimolar concentration of sucrose to improve neuronal viability. The standard aCSF contained the following (in $\mathrm{mm}$ ): $130 \mathrm{NaCl}, 3 \mathrm{KCl}, 1.3 \mathrm{MgSO}_{4}, 1.4$ $\mathrm{NaH}_{2} \mathrm{PO}_{4}, 2.4 \mathrm{CaCl}_{2}, 11$ glucose, and 5 HEPES, and was bubbled with $100 \% \mathrm{O}_{2}$. The hemislices were maintained submerged in a holding chamber in oxygenated aCSF at room temperature, where they were allowed to equilibrate for $1.5-2 \mathrm{~h}$ before being transferred to the recording chamber.

In the experiments using the glial metabolic toxin fluorocitrate (Paulsen et al., 1987; Fonnum et al., 1997; Gordon et al., 2005), half of the bisected slices were incubated in aCSF containing DL-fluorocitric acid (FCA; $100 \mu \mathrm{M}$, with barium salt removed by precipitation;Paulsen et al., 1987) for at least $2 \mathrm{~h}$ before being transferred to a recording chamber, where they were perfused with FCA-containing aCSF throughout the experiments, which lasted for up to an additional $4 \mathrm{~h}$. The other half of bisected slices served as controls and were incubated in and perfused with standard aCSF.

Electrophysiological methods. Individual neurons in hypothalamic slices were visualized on a fixed-stage upright microscope using infrareddifferential interference contrast optics. Whole-cell patch-clamp recordings were performed at $30-32^{\circ} \mathrm{C}$ using electrodes with a tip resistance of 3-4 M $\Omega$. The internal recording solutions contained either (in mM) 110 D-gluconic acid, $110 \mathrm{CsOH}, 10 \mathrm{CsCl}, 1 \mathrm{MgCl}_{2}, 1 \mathrm{CaCl}_{2}, 10$ EGTA, 2 Mg-ATP, $0.3 \mathrm{Na}-\mathrm{GTP}$, and $10 \mathrm{HEPES}$; or $120 \mathrm{CsCl}, 2 \mathrm{MgCl}_{2}, 1 \mathrm{CaCl}_{2}, 11$ EGTA, $2 \mathrm{Mg}$-ATP, $0.3 \mathrm{Na}-\mathrm{GTP}$, and 30 HEPES. Magnocellular neuroendocrine cells were voltage-clamped at a holding potential of $0 \mathrm{mV}$, using the $\mathrm{CsOH}$ patch solution, or $-60 \mathrm{mV}$, using the $\mathrm{CsCl}$ patch solution, to record IPSCs. The latter solution was used for the majority of recordings of IPSCs to reverse the $\mathrm{GABA}_{\mathrm{A}}$ receptor-mediated currents and increase the $\mathrm{Cl}^{-}$driving force, as well as to avoid the need to hold the cell membrane at a depolarized potential where depolarization-induced endocannabinoid synthesis could occur. In the study of depolarization-induced endocannabinoid release, QX 314 bromide ( $5 \mathrm{~mm}$ ) was added to the internal recording solution to record evoked IPSCs. All recordings were performed in voltage-clamp mode using a Multiclamp 700A amplifier and pCLAMP 9 software (Molecular Devices). The series resistance was monitored at the beginning of recordings, following a stabilization period, and following experimental manipulations; cells that had an unstable baseline or that showed a series resistance change of $>20 \%$ from initial values of $8-20 \mathrm{M} \Omega$ over the course of recordings were excluded from data analysis. Data were low-pass filtered at $2 \mathrm{kHz}$, digitized at 5 $\mathrm{kHz}$, and saved on a personal computer for off-line analysis. To isolate miniature IPSCs (mIPSCs), tetrodotoxin (TTX; $1 \mu \mathrm{M}$ ) was added to the aCSF to block spike-mediated neurotransmitter release and 6,7dinitroquinoxaline-2,3-dione (DNQX, $20 \mu \mathrm{M}$ ), and D-(-)-2-amino-5phosphonopentanoic acid (AP5; $40 \mu \mathrm{M})$ were included in the aCSF to block ionotropic glutamate receptor-mediated synaptic currents. To focus on the fast, nongenomic actions of glucocorticoids, 3 min epochs of mIPSCs at 7-10 min into drug treatments were analyzed and compared with 3 min control epochs acquired just before the treatments for mean frequency, amplitude, and decay time (defined as the time from peak to $63 \%$ decay of the mIPSC) using the Minianalysis 6.0 program (Synaptosoft).

In experiments focused on activity-dependent endocannabinoid release (depolarization-induced suppression of inhibition; DSI), DSI was induced by depolarizing neurons from a holding potential of $-60 \mathrm{mV}$ to $0-10 \mathrm{mV}$ for $10 \mathrm{~s}$. IPSCs evoked by extracellular stimulation (eIPSCs) at $50-70 \%$ maximal amplitude were used to assess DSI; extracellular stimulation (Winston stimulator, A-65, Winston Electronics; Grass S487 stimulator, Grass Technologies) was delivered at $0.2 \mathrm{~Hz}$ via a concentric bipolar electrode placed dorsal-medial to the SON in the presence of the ionotropic glutamate receptor antagonists DNQX and AP5. Evoked IPSCs were confirmed as GABAergic by their blockade with the $\mathrm{GABA}_{\mathrm{A}}$ receptor antagonist bicuculline methiodide $(10 \mu \mathrm{M} ; n=4)$.

Drug application. A water-soluble form of dexamethasone [(2Hydroxypropyl)- $\beta$-cyclodextrin-conjugated dexamethasone; SigmaAldrich] was used in these experiments. The rapid, dose-dependent effects of both the endogenous glucocorticoid corticosterone and the synthetic glucocorticoid dexamethasone on synaptic transmission in magnocellular neurons have been characterized in previous studies and found to be similar (Di et al., 2005a). Here we used a saturating dose of 1 $\mu \mathrm{M}$ dexamethasone. The following drugs were stored as $1000 \times$ stock solutions at $-20^{\circ} \mathrm{C}$ and were dissolved to their final concentrations in aCSF before their application in the bath perfusion: TTX (SigmaAldrich), DNQX, AP5, the CB1 receptor antagonist SR141716 (kindly provided by the NIMH Chemical Synthesis and Drug Supply Program), selective DGL inhibitor tetrahydrolipstain (THL; Sigma-Aldrich) and the endocannabinoid transporter blocker OMDM-2 (Tocris Bioscience). Dextran (MW 35-45k, Sigma-Aldrich) was dissolved directly in aCSF at its final concentration.

Data analysis. All data are expressed as mean \pm SE of the mean. Statistical comparisons of electrophysiological data were performed using the Student's paired $t$ test for within-cell group comparisons and the Student's unpaired $t$ test for between-cell group comparisons. A one-way repeated-measures ANOVA was used for multiple comparisons, followed by Tukey's test as needed. Probability values of $<0.05$ were considered significant for all comparisons.

For DSI experiments, peak amplitudes of eIPSCs were averaged in $10 \mathrm{~s}$ bins (average of two eIPSCs at $5 \mathrm{~s}$ intervals) for $1 \mathrm{~min}$ following the depolarization and normalized to the baseline value (100\%), which represents the average of eIPSCs over the $1 \mathrm{~min}$ immediately before the depolarization. Each data point represents an average of at least 5 separate trials. DSI data were analyzed by the one-way repeated-measures ANOVA followed by the Dunnett's test. 

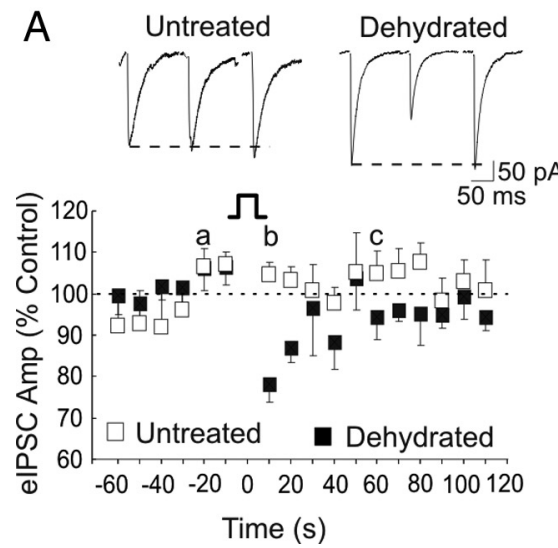
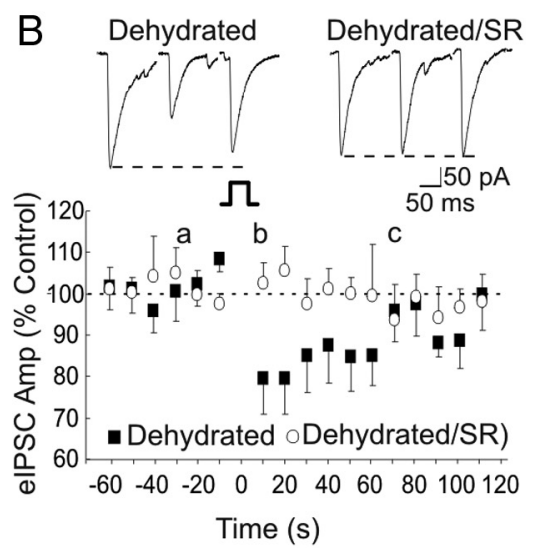

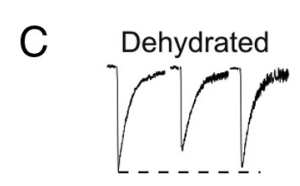

Dehydrated/

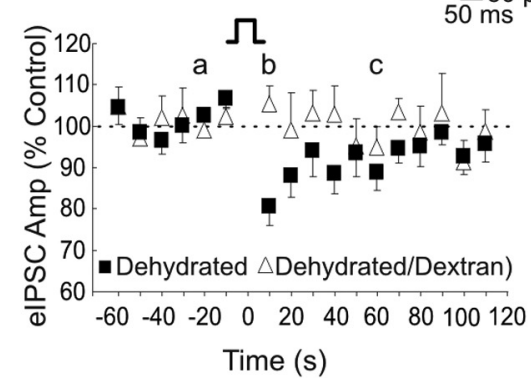

Figure 1. Depolarization-induced endocannabinoid suppression of GABA synaptic responses following dehydration-induced glial retraction. Averaged evoked responses ( $n=4$, top) and rolling normalized mean evoked IPSC amplitudes (percentge of baseline, bottom) are shown for each condition. Postsynaptic depolarization (square pulse) occurred at time 0 . In each time series, $\boldsymbol{a}$ - $\mathbf{c}$ refers to the time points of the first, second, and third averaged responses for each of the conditions. $A$, Postsynaptic depolarization had no effect on the eIPSC amplitude (eIPSC Amp) in SON neurons from normally hydrated (untreated) rats, but caused a transient decrease in eIPSC amplitude (i.e., DSI) in SON neurons from dehydrated rats (Dehydrated). $\boldsymbol{B}$, The DSI seen in SON neurons from dehydrated rats (Dehydrated) was blocked by the (B1 receptor antagonist SR141716 (Dehydrated/SR). C, The DSI evoked in SON neurons from dehydrated rats (Dehydrated) was also blocked by increasing extracellular viscosity with dextran (Dehydrated/Dextran).

\section{Results}

We and others have shown that magnocellular neuroendocrine cells generate a depolarization-induced endocannabinoid suppression of glutamate synaptic excitation (Hirasawa et al., 2004; Di et al., 2005a), but not DSI (Di et al., 2005a). Our previous studies also demonstrated rapid synapse-specific glucocorticoid effects on synaptic inputs to hypothalamic magnocellular neuroendocrine cells that consist of an endocannabinoid-dependent suppression of transmitter release at glutamate synapses, but not at GABA synapses (Di et al., 2005b, 2009). This glutamate synapse specificity of depolarization- and glucocorticoid-induced endocannabinoid actions occurs despite the fact that both glutamate and GABA synapses express functional CB1 receptors (Di et al., 2009). Here, we manipulated astrocyte coverage of magnocellular neurons and glial metabolic function, as well as cannabinoid uptake and the viscosity of the extracellular environment, to determine whether the failure of depolarization- and glucocorticoidinduced retrograde endocannabinoid release to affect GABA synapses on magnocellular neurons is due to astrocyte buffering mechanisms.

\section{Depolarization-induced endocannabinoid modulation of GABA synapses following dehydration}

Dehydration induces a structural and functional plasticity of neuronal-glial interactions in the hypothalamic SON that is characterized by glial retraction from around magnocellular neurons (Theodosis et al., 2008). This causes the loss of glial coverage of synapses and reduced glial uptake of chemical neurotransmitters, which leads to an increase in the extracellular levels of the neurotransmitters and transmitter diffusion to presynaptic receptors and adjacent synapses (Oliet et al., 2001; Boudaba et al., 2003; Piet et al., 2004). Here, we tested whether the decreased glial coverage of magnocellular neurons caused by chronic dehydration would lead to an emergent depolarization-induced endocannabinoid suppression of GABA release, or DSI. Whole-cell patch-clamp recordings were performed in SON magnocellular neuroendocrine cells in acute hypothalamic slices and GABAergic synaptic currents were evoked by extracellular electrical stimulation in the presence of the ionotropic glutamate receptor antagonists DNQX and AP-5 (see Materials and Methods). After obtaining a stable baseline of eIPSCs, the membrane potential of voltageclamped neurons was stepped from a holding potential of -60 $\mathrm{mV}$ to a depolarized potential of $0-10 \mathrm{mV}$ for $10 \mathrm{~s}$. This stimulation paradigm failed to elicit DSI in SON neurons in slices from normally hydrated rats; it had no effect on the mean amplitude of eIPSCs (baseline 296.9 $\pm 49.7 \mathrm{pA}$ vs $318.1 \pm 48.9 \mathrm{pA}$ at $10 \mathrm{~s}$ and $295.7 \pm 55.5 \mathrm{pA}$ at $20 \mathrm{~s}$ postdepolarization; $p=0.3$ and 0.9 , respectively; $n=14$ ). However, the same stimulation paradigm caused a transient decrease in the amplitude of the eIPSCs in SON neurons in slices from dehydrated rats; the mean amplitude of eIPSCs was reduced by $20 \%$ at $10 \mathrm{~s}$ and by $12 \%$ at 20 s postdepolarization (baseline $332.9 \pm 68.1 \mathrm{pA}$ vs $261.7 \pm 64.6 \mathrm{pA}$ at $10 \mathrm{~s}$ and $278.7 \pm 71.9 \mathrm{pA}$ at $20 \mathrm{~s}$ postdepolarization; $p<0.01, n=14)$, and recovered back to the baseline amplitude after 30-60 s (Fig. 1A). The DSI in SON neurons from dehydrated rats was blocked by the CB1 receptor antagonist SR141716 (1 $\mu \mathrm{M}$; baseline $310.9 \pm$ $66.6 \mathrm{pA}$ vs $310.1 \pm 62.4 \mathrm{pA}$ at $10 \mathrm{~s}$ postdepolarization; $p=0.8$, $n=7$; Fig. $1 B$ ), indicating that it was mediated by endocannabinoid activation of presynaptic CB1 receptors. Thus, whereas activity-dependent endocannabinoid release had no effect on evoked GABA synaptic currents under normal conditions, a depolarization-induced endocannabinoid suppression of GABA release, or DSI, emerged under conditions of reduced glial coverage following chronic dehydration.

In addition to their uptake function, another function that astrocytes may serve in the control of extracellular neuronal signaling is to provide a physical barrier to limit neurotransmitter diffusion in the extracellular space. With the retraction of glial processes under conditions such as dehydration (Miyata et al., 1994), the extracellular diffusion barrier is reduced, which should lead to a greater diffusion of extracellular signals and possible spillover effects at neighboring synapses (Piet et al., 2004). Here, we tested this hypothesis by introducing dextran, a large, membrane-impermeant molecule, into the extracellular space of slices from dehydrated rats to increase the viscosity of the extracellular matrix and pharmacologically reverse the decreased diffusion barrier seen with dehydration-induced glial retraction. We added $5 \%$ dextran $(\mathrm{w} / \mathrm{v})$ to the perfusion medium, which should double the viscosity of the extracellular milieu without significantly affecting the osmolarity of the solution (Min et al., 


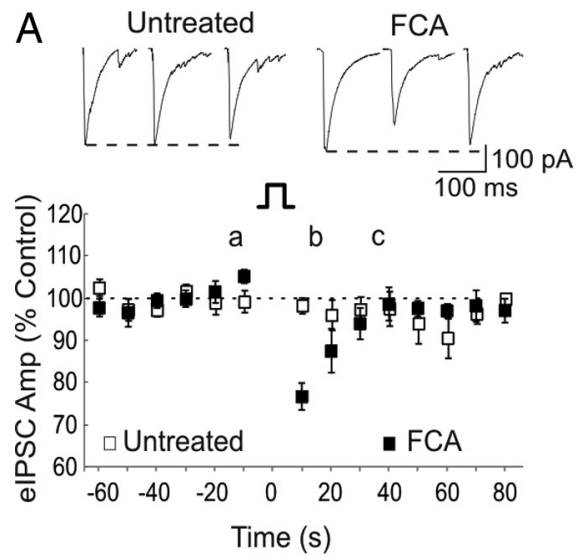

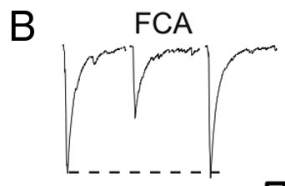
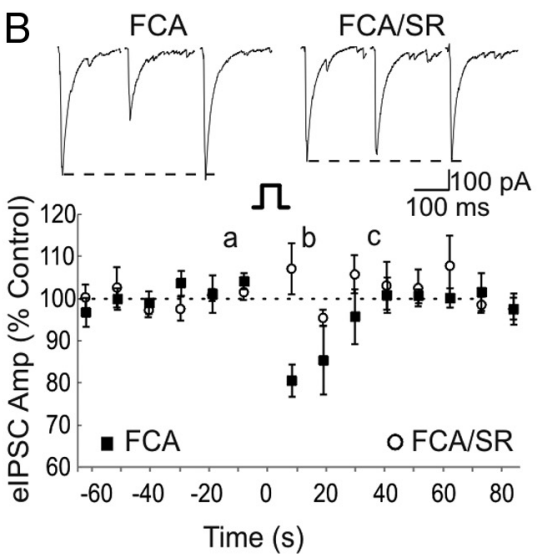
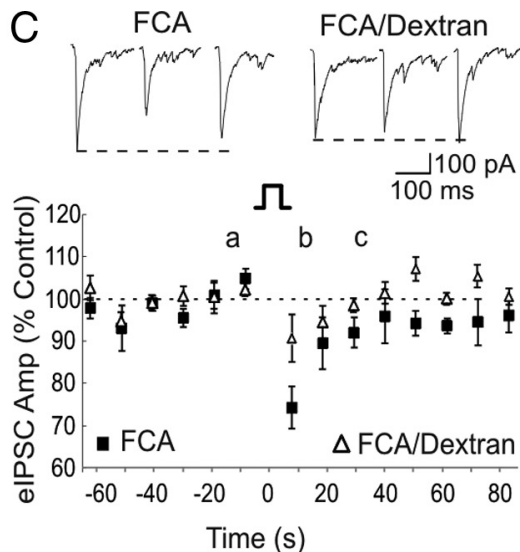

Figure 2. Depolarization-induced endocannabinoid suppression of GABA synaptic responses following gliotoxin flurocitrate treatment. Averaged evoked responses ( $n=4$, top) and rolling normalized mean evoked IPSC amplitudes (percentage of baseline, bottom) are shown for each condition. Postsynaptic depolarization (square pulse) occurred at time 0 . In each time series, $\boldsymbol{a}-\boldsymbol{c}$ refers to the time points of the first, second, and third averaged responses for each of the conditions. A, Postsynaptic depolarization had no effect on the elPSC amplitude (eIPSC Amp) in SON neurons from normally (Untreated) rats, but caused a transient decrease in eIPSC amplitude (i.e., DSI) in SON neurons from fluorocitrate-treated slices (FCA). $\boldsymbol{B}$, The DSI seen in SON neurons from fluorocitrate-treated rats (FCA) was blocked by the CB1 receptor antagonist SR141716 (FCA/SR). C, The DSI evoked in SON neurons from fluorocitrate-treated rats (FCA) was also blocked by increasing extracellular viscosity with dextran (FCA/Dextran).

1998; Perrais and Ropert, 2000; Nielsen et al., 2004). Dextran reversed the suppression of evoked IPSCs induced by postsynaptic depolarization of SON neurons in slices from dehydrated rats (Fig. 1C). The mean normalized evoked IPSC amplitudes were $98 \%$ of baseline at $10 \mathrm{~s}$ and $103 \%$ of baseline at $20 \mathrm{~s}$ postdepolarization (baseline $308.9 \pm 35.6 \mathrm{pA}$ vs $298.7 \pm 31.8 \mathrm{pA}$ at $10 \mathrm{~s}$ postdepolarization; $p=0.6, n=7)$. These findings demonstrated that decreasing extracellular diffusion with dextran in slices from dehydrated rats prevented the activity-dependent endocannabinoid effect on GABA release caused by glial retraction.

To determine whether the DSI recorded in magnocellular neurons from dehydrated rats was specific to OT or VP neurons, we conducted a subset of experiments in which identified VP and OT neurons were recorded in slices from transgenic rats that express either a VP-GFP (Ueta et al., 2005) or an OT-RFP fusion protein (Katoh et al., 2011). The same DSI stimulation paradigm induced a comparable decrease in the amplitude of evoked IPSCs in both VP neurons and OT neurons in slices from dehydrated VP-GFP and OT-RFP transgenic rats, respectively. In identified VP neurons, the normalized mean amplitude of evoked IPSCs was reduced by $25 \%$ at $10 \mathrm{~s}$ and by $18 \%$ at $20 \mathrm{~s}$ postdepolarization (baseline $303.8 \pm 85.6 \mathrm{pA}$ vs $246.2 \pm 71.3 \mathrm{pA}$ at $10 \mathrm{~s}$ and $272.4 \pm$ $84.2 \mathrm{pA}$ at $20 \mathrm{~s}$ postdepolarization; $p<0.01, n=10$ ), and recovered back to baseline in 30-60 s. In identified OT neurons, the normalized mean amplitude of evoked IPSCs was reduced by $24 \%$ at $10 \mathrm{~s}$ and by $16 \%$ at $20 \mathrm{~s}$ postdepolarization (baseline $442.2 .8 \pm 47.8 \mathrm{pA}$ vs $373.4 \pm 62.9 \mathrm{pA}$ at $10 \mathrm{~s}$ and $385.3 .4 \pm 60.2$ $\mathrm{pA}$ at $20 \mathrm{~s}$ postdepolarization; $p<0.01, n=9$ ), and recovered back to baseline in 30-60 s. These data indicate, therefore, that the depolarization-induced endocannabinoid suppression of GABA release occurs in both VP and OT neurons under conditions of reduced glial coverage following chronic dehydration.

\section{Depolarization-induced endocannabinoid modulation of GABA synapses following blockade of glial metabolism}

To determine whether the loss of glial reuptake mechanisms contributed to the depolarization-induced suppression of evoked synaptic GABA currents in SON neurons from dehydrated rats, we tested for DSI in SON neurons in slices from normally hydrated rats that were treated with the glial toxin FCA (see Materials and Methods). FCA is taken up selectively by glial cells and blocks glial metabolism by inhibiting the citric acid cycle (Paulsen et al., 1987; Fonnum et al., 1997; Deleuze et al., 1998), but does not cause detectable ultrastructural changes in glial coverage of neurons (Paulsen et al., 1987). In a DSI paradigm identical to that of the previous series of experiments, a stable baseline of evoked IPSCs was achieved before the membrane potential of SON neurons was stepped from $-60 \mathrm{mV}$ to $0-10 \mathrm{mV}$ for $10 \mathrm{~s}$. As before, this postsynaptic depolarization had no significant effect on the amplitude of evoked IPSCs in neurons in untreated slices from normally hydrated rats (baseline: $620.4 \pm 113.7 \mathrm{pA}$ vs $598.4 \pm 101.2 \mathrm{pA}$ at $10 \mathrm{~s}$ postdepolarization; $p=0.77 ; n=7)$. The same postsynaptic depolarization of SON neurons in slices pretreated with FCA, however, caused a transient decrease in the amplitude of the evoked IPSCs (Fig. 2A). In FCA-treated slices, the normalized mean amplitude of evoked IPSCs was reduced by $22 \%$ at $10 \mathrm{~s}$ and by $12 \%$ at $20 \mathrm{~s}$ postdepolarization (baseline $553.1 \pm 72.6 \mathrm{pA}$ vs $428.6 \pm 55.9 \mathrm{pA}$ at $10 \mathrm{~s}$ and $468.1 \pm 58.1 \mathrm{pA}$ at $20 \mathrm{~s}$ postdepolarization; $p<0.05$ for both time points, $n=15$ ), and recovered back to the baseline amplitude in $\sim 30 \mathrm{~s}$ (Fig. $2 \mathrm{~A}$ ). The DSI in slices treated with FCA was also blocked by the CB1 receptor antagonist SR141716 ( $1 \mu \mathrm{M}$; baseline $520.3 \pm 89.9 \mathrm{pA}$ vs $530.2 \pm 84.5 \mathrm{pA}$ at $10 \mathrm{~s}$ postdepolarization; $p=0.13, n=9$; Fig. $2 B$ ), indicating that, similar to slices from dehydrated rats, the depolarization-induced suppression of GABA synaptic currents in slices treated with FCA was mediated by endocannabinoid activation of presynaptic $\mathrm{CB} 1$ receptors. The emergence, therefore, of DSI following the loss of glial function in these two experiments suggests the spillover of activity-dependent endocannabinoid onto GABA synapses.

We again introduced dextran into the bath perfusion $(5 \%$ $\mathrm{w} / \mathrm{v}$ ) to determine whether increasing the viscosity of the extracellular fluid would increase the endocannabinoid diffusion barrier in FCA-treated slices. Dextran decreased the DSI in FCAtreated slices to a nonsignificant level, although there remained a trend toward a suppression of IPSCs (Fig. 2C); the mean normalized evoked IPSC amplitudes were $91 \%$ of baseline at $10 \mathrm{~s}$ and $95 \%$ of baseline at $20 \mathrm{~s}$ postdepolarization (baseline: $521.1 \pm 77.5 \mathrm{pA}$ vs $478.4 \pm 82.1 \mathrm{pA}$ at $10 \mathrm{~s}$ postdepolarization; $p=0.11, n=9$ ). Therefore, decreasing extracellular diffusion with dextran attenuated the depolarization-induced endocannabinoid suppression of GABA release caused by blocking glial metabolism. 
A
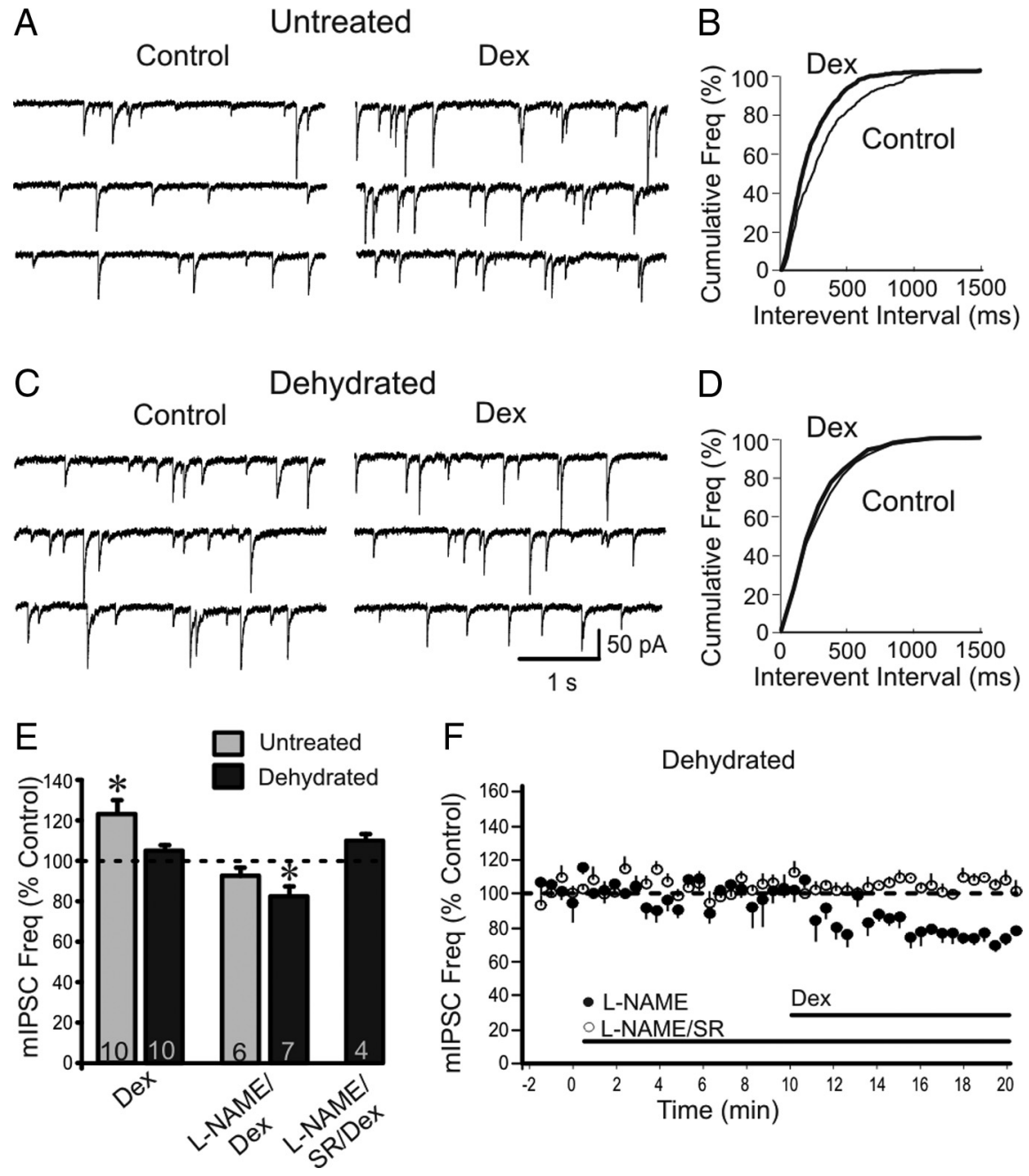

F

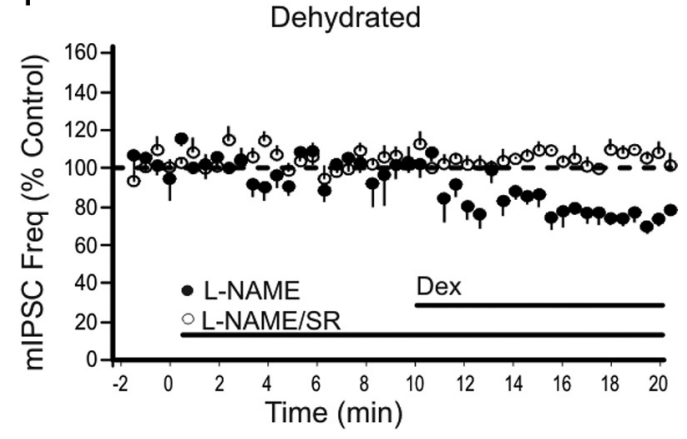

Figure 3. Glucocorticoid-induced endocannabinoid suppression of synaptic GABA currents following dehydration-induced glial retraction. $\boldsymbol{A}$, Recording of the effect of Dex on mIPSCs in an SON neuron from a normally hydrated rat (Untreated). Dex caused a clear increase in the frequency of mIPSCs. $\boldsymbol{B}$, Cumulative frequency plot of the Dex-induced decrease in mIPSC interevent interval, from the recording shown in $\boldsymbol{A}$. C, Recording of the effect of Dex on mIPSCs in an SON neuron from a dehydrated rat, in which Dex failed to increase the frequency of mIPSCs. D, Cumulative frequency plot of the lack of effect of Dex on mIPSC interevent interval, from the recording shown in $\boldsymbol{C}$. $\boldsymbol{E}$, Mean changes in mIPSC frequency as a percentage of control before (Dex) and following blockade of N0 synthase (L-NAME/Dex) and both CB1 receptors and N0 synthase (L-NAME/SR/Dex) in SON neurons from normally hydrated (Untreated) and dehydrated rats. $\boldsymbol{F}$, Normalized running average ( $30 \mathrm{~s}$ bin width) of mIPSC frequency. The Dex-induced increase in mIPSC frequency (Dex) seen in SON neurons from untreated rats was lost in SON neurons from dehydrated rats. Inhibiting NO synthase revealed a Dex-induced decrease in the mIPSC frequency in neurons from dehydrated rats (L-NAME), which was blocked by blocking CB1 receptors (L-NAME/SR). Calibration bars in $\boldsymbol{C}$ apply to both $\boldsymbol{A}$ and $c_{i}^{*} p<0.05$

\section{Glucocorticoid-induced endocannabinoid modulation of GABA synapses following glial retraction}

Glucocorticoids induce a rapid synthesis and retrograde release of endocannabinoid, which selectively suppresses presynaptic glutamate release, but not GABA release, via activation of presynaptic CB1 receptors (Di et al., 2003). At GABA synapses on magnocellular neurons, on the other hand, glucocorticoids elicit a rapid nitric oxide (NO)-dependent facilitation of GABA release, which is not affected by blocking cannabinoid receptors (Di et al., 2009). Here, we tested for an emergent glucocorticoid-induced endocannabinoid suppression of GABA release that counteracts the NO facilitation of GABA release following dehydrationinduced glial retraction.

Miniature IPSCs were recorded in SON magnocellular neuroendocrine cells in slices from normally hydrated and chroni- cally dehydrated rats. GABAergic mIPSCs were isolated in the presence of TTX (1 $\mu \mathrm{M})$ and the ionotropic glutamate receptor antagonists DNQX $(20 \mu \mathrm{M})$ and AP5 $(40 \mu \mathrm{M})$. There was an increase in the frequency of baseline mIPSCs in SON neurons following chronic dehydration (normally hydrated $1.3 \pm 0.1 \mathrm{~Hz}$ vs dehydrated $1.6 \pm 0.1 \mathrm{~Hz} ; p<0.05 ; n=51$ and 44 , respectively), which is consistent with previous observations (Di and Tasker, 2004). In SON neurons recorded in slices from normally hydrated rats, bath application of the synthetic glucocorticoid dexamethasone (Dex, $1 \mu \mathrm{M}$ ) caused a 25\% increase in the mean frequency of mIPSCs (from $1.5 \pm 0.3 \mathrm{~Hz}$ to $1.9 \pm 0.3 \mathrm{~Hz} ; p<$ $0.05 ; n=10$; Fig. $3 A, B, E)$, but had no effect on mIPSC amplitude (71.4 \pm 16.3 pA vs $71.8 \pm 16.1 \mathrm{pA}$ ) or decay kinetics $(13.7 \pm 0.9 \mathrm{~ms}$ vs $13.6 \pm 1.0 \mathrm{~ms})$. This was similar to the rapid facilitatory effect of glucocorticoids on GABAergic synaptic inputs to magnocellular neurons that was dependent on NO release in our previous study (Di et al., 2009). As in that study, the Dex-induced facilitation of mIPSCs was insensitive to blockade of $\mathrm{CB} 1$ receptors with SR141716 ( $1 \mu \mathrm{M} ; p>0.05$, data not shown), indicating that endocannabinoids did not contribute to the effect; however, it was completely blocked by the inhibition of NO synthesis with the NO synthase blocker L-NAME $(50 \mu \mathrm{M}$; Fig. $3 E)$, confirming the NO dependence and $\mathrm{CB} 1$ independence of the glucocorticoidinduced facilitation of GABA release onto SON magnocellular neurons in normally hydrated rats.

In contrast, in SON neurons recorded in slices from dehydrated rats, bath application of Dex $(1 \mu \mathrm{M})$ had no effect on the mIPSC frequency (baseline: $1.7 \pm 0.3 \mathrm{~Hz}$ vs Dex: $1.8 \pm 0.4 \mathrm{~Hz} ; p=0.80 ; n=10$; Fig. $3 C-E)$. If the loss of the glucocorticoidinduced NO facilitation of GABA release was due to an opposing effect of endocannabinoid at GABA terminals under conditions of reduced glial coverage, then inhibiting the effect of NO should reveal an endocannabinoid suppression of GABA release, which should be blocked by inhibiting CB1 receptors. We tested this by sequentially blocking NO synthesis and CB1 receptors in slices from dehydrated rats. Note that, as stated above, in slices from normally hydrated rats, blocking $\mathrm{CB} 1$ receptors had no effect on, and blocking NO synthesis completely blocked, the glucocorticoid facilitation of GABA release onto magnocellular neurons. In slices from dehydrated rats, following blockade of NO synthesis with the NO synthase blocker L-NAME (50 $\mu \mathrm{M})$, Dex $(1 \mu \mathrm{M})$ caused a rapid decrease in mIPSC frequency (to $83 \%$ of baseline; from $1.7 \pm 0.5 \mathrm{~Hz}$ to $1.4 \pm 0.4 \mathrm{~Hz} ; p<0.05 ; n=7$ ), which was reversed by blocking CB1 receptors with SR141716 (1 $\mu \mathrm{M}$; Fig. $3 E, F)$. As further support for the opposing effects of endocannabinoid and NO on GABA release in slices from dehy- 
drated rats, blockade of CB1 receptors alone caused Dex ( $1 \mu \mathrm{M})$ to elicit a significant $25 \%$ increase in mIPSC frequency, which was similar to the facilitatory effect of Dex on mIPSCs in slices from untreated rats (data not shown). These data support the hypothesis that the null effect of glucocorticoid on GABA synaptic signaling in SON neurons in slices from dehydrated rats is the result of the opposing actions of the two glucocorticoid-induced retrograde messengers, endocannabinoid and NO, on GABA release. Dex was without effect on the amplitude or the decay time of mIPSCs in SON neurons recorded in slices from both normally hydrated and dehydrated rats (data not shown).

Previous studies have shown that glial retraction during dehydration and lactation causes an increase in the extracellular glutamate concentration and activation of presynaptic metabotropic glutamate receptors (Di and Tasker, 2004; Piet et al., 2004), which could contribute to the rapid glucocorticoid effect on GABA release. Blockade of metabotropic glutamate receptors with LY341495, at a receptor subtype-nonselective concentration of $100 \mu \mathrm{M}$, had no effect on the Dex-induced increase in mIPSC frequency in SON neurons from untreated rats $(122 \pm 2 \%$ of baseline, $n=5$ ) or on the null effect of Dex on mIPSC frequency in SON neurons from dehydrated rats $(98 \pm 2 \%$ of baseline, $n=7$ ).

We showed previously that glucocorticoids induce a similar endocannabinoid-mediated suppression of both spontaneous and evoked synaptic glutamate release onto magnocellular neurons (Di et al., 2009), which suggests that the presynaptic CB1 receptor signaling mechanism activated by glucocorticoidinduced endocannabinoid release modulates vesicle pools for both spontaneous and evoked glutamate release. Here, we tested whether the suppression of GABA release by glucocorticoidinduced endocannabinoid spillover seen with spontaneous release in slices from dehydrated rats could also be seen with evoked GABA responses. We also determined whether the glucocorticoid-induced endocannabinoid spillover onto GABA synapses was specific to VP or OT neurons using slices from dehydrated VP-GFP and OT-RFP transgenic rats. Thus, in recordings from identified VP neurons in slices from dehydrated rats, following blockade of NO synthesis with L-NAME (50 $\mu \mathrm{M})$, bath application of Dex $(1 \mu \mathrm{M})$ caused a rapid $28 \%$ decrease in the mean frequency of mIPSCs (from $2.0 \pm 0.3 \mathrm{~Hz}$ to $1.5 \pm 0.2$ $\mathrm{Hz} ; p<0.05 ; n=7)$ and a $25 \%$ decrease in the amplitude of evoked IPSCs (from 498.1 \pm 50.9 pA to $315.8 \pm 42.7$ pA; $p<$ $0.05 ; n=5$ ). In recordings from identified OT neurons from dehydrated rats, in the presence of L-NAME, bath application of $\operatorname{Dex}(1 \mu \mathrm{M})$ caused a rapid $22 \%$ decrease in the mean frequency of mIPSCs (from $1.9 \pm 0.2 \mathrm{~Hz}$ to $1.5 \pm 0.2 \mathrm{~Hz} ; p<0.01 ; n=6$ ) and a $21 \%$ decrease in the mean amplitude of eIPSCs (from $395.1 \pm$ $33.1 \mathrm{pA}$ to $312.2 \pm 24.2 \mathrm{pA} ; p<0.01 ; n=5$ ). These data indicate that the glucocorticoid-induced endocannabinoid modulation of GABA synapses occurs in both VP and OT magnocellular neuroendocrine cells, and at the level of both evoked and spontaneous GABA release under conditions of reduced glial coverage following chronic dehydration.

We next tested whether increasing the viscosity of the perfusion medium with dextran would reverse the glucocorticoidinduced endocannabinoid suppression of GABA release in dehydrated rats by reducing extracellular diffusion. Dextran ( $5 \%$ w/v) by itself had no effect on the frequency, amplitude or decay time of mIPSCs recorded in SON neurons in slices from normal or dehydrated rats, and had no effect on the Dex-induced NO facilitation of mIPSC frequency in slices from normally hydrated rats (Fig. 4). However, dextran restored the glucocorticoid-

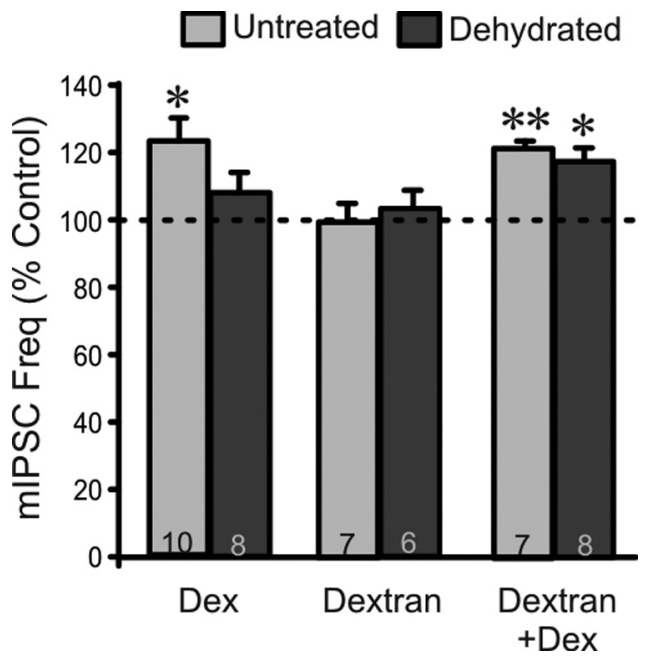

Figure 4. Glucocorticoid-induced endocannabinoid spillover onto GABA synapses following glial retraction is reversed by increasing extracellular viscosity. In slices from normally hydrated rats, dextran (5\%) alone had no effect on mIPSC frequency, and did not block the Dex-induced increase in mIPSC frequency. In SON neurons from dehydrated rats, dextran alone (Dextran) had no effect on the mIPSC frequency, but restored the facilitatory effect of dexamethasone on mIPSC frequency (Dextran + Dex) that was lost with dehydration (Dex); ${ }^{*} p<0.05$; ${ }^{* *} p<0.01$.

induced facilitation of GABA release that was lost in SON neurons from dehydrated rats due to the opposing inhibitory effect of endocannabinoid on GABA release. Thus, bath application of $\operatorname{Dex}(1 \mu \mathrm{M})$, although without effect on MIPSC frequency in SON neurons from dehydrated rats as reported above, induced an $18 \%$ increase in mIPSC frequency in the presence of dextran (from $1.5 \pm 0.3 \mathrm{~Hz}$ to $1.7 \pm 0.3 \mathrm{~Hz} ; p<0.05 ; n=8$; Fig. 4 ), which was comparable to the facilitatory effect of Dex on mIPSCs observed in slices from normally hydrated rats. These observations support the hypothesis that glucocorticoid-induced endocannabinoid is impeded from accessing CB1 receptors on GABA synaptic terminals by a diffusion barrier that restricts its range of action.

\section{Glucocorticoid-induced endocannabinoid modulation of GABA synapses following blockade of glial metabolism}

To determine whether the loss of endocannabinoid uptake by astrocytes was responsible for the glucocorticoid-induced endocannabinoid suppression of GABA release seen in SON neurons in slices from dehydrated rats, we tested for a similar effect of glucocorticoid modulation of synaptic GABA release onto SON neurons in slices from normally hydrated rats that were treated with the glial toxin FCA (see Materials and Methods). As observed in the previous series of experiments, bath application of Dex $(1 \mu \mathrm{M})$ caused a $19 \%$ increase in mIPSC frequency in SON neurons in untreated slices from normally hydrated rats (from $2.0 \pm 0.3 \mathrm{~Hz}$ to $2.5 \pm 0.4 \mathrm{~Hz} ; p<0.05 ; n=8$; Fig. $5 A, B, E)$. This effect was mediated by NO release, as it was completely abolished by blocking NO synthase activity with L-NAME (50 $\mu \mathrm{M}$; Fig. $5 E$ ) and was insensitive to blockade of CB1 receptors with SR141716 (1 $\mu \mathrm{M}$; data not shown).

As in slices from dehydrated rats, in slices exposed to FCA (100 $\mu \mathrm{M})$, Dex $(1 \mu \mathrm{M})$ had no effect on mIPSC frequency (baseline $2.3 \pm$ $0.6 \mathrm{~Hz}$ vs $2.3 \pm 0.9 \mathrm{~Hz}$ in Dex; $p=0.88, n=10$; Fig. $5 C-E$ ). To determine whether the loss of the rapid glucocorticoid-induced facilitation of GABA release in FCA-treated slices was due to the suppressive action of endocannabinoid opposing the facilitatory action of NO at GABA synapses, we tested SON neurons from 
A

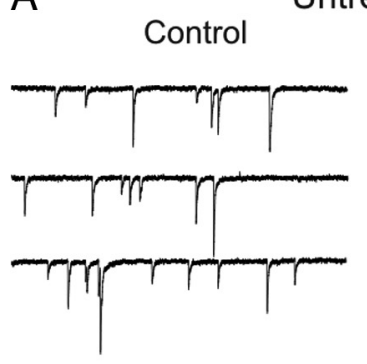

B

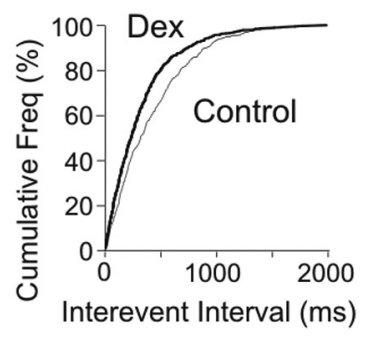

C

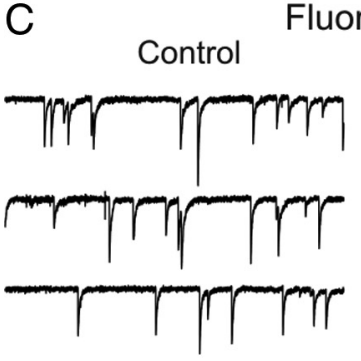

E

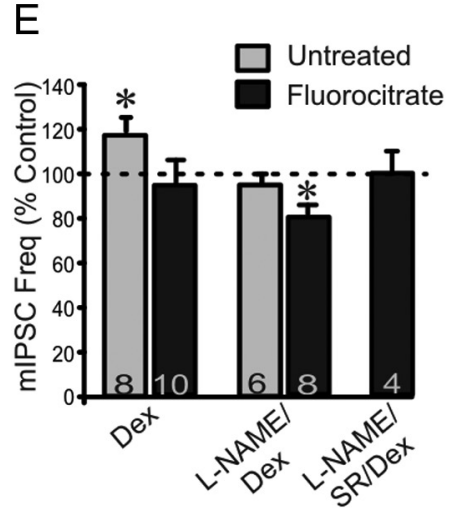

\section{Dex}

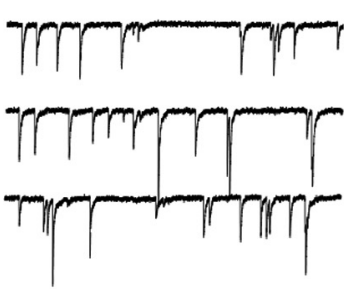

Fluorocitrate

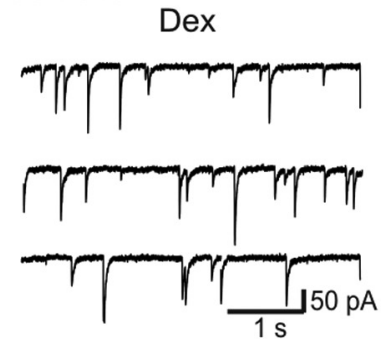

D

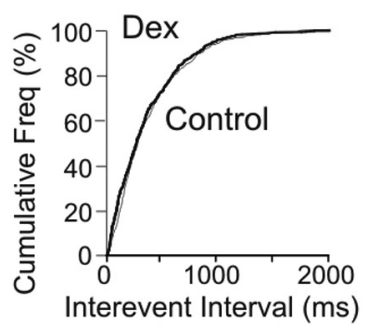

CB1 receptor antagonist SR141716 $(1 \mu \mathrm{M})$ was applied to block CB1 receptors alone in the FCA-treated slices, the Dex-induced, NO-dependent facilitation of GABA release was rescued (data not shown). The emergence of a Dex-induced endocannabinoid suppression of GABA release following the loss of glial function in experiments in slices from dehydrated rats and in FCA-treated slices suggests a glucocorticoid-induced spillover effect of endocannabinoid at GABA synapses.

Evoked, but not tonic, endocannabinoid actions depend on 2-AG

Recent evidence suggests that different endocannabinoids may be responsible for the effects of tonic and evoked endocannabinoid release at some synapses. Thus, activity-dependent endocannabinoid effects are often dependent on 2-AG synthesis and anandamide is responsible for tonic CB1 receptor activation in a subset of GABA synapses in hippocampal slice cultures (Kim and Alger, 2010; Alger, 2012). Also, although both anandamide and 2-AG are synthesized in slices of PVN in response to glucocorticoid application (Malcher-Lopes et al., 2006) and afferent stimulation (Di et al., 2005a), in vivo anandamide levels were shown to decrease and 2-AG levels to increase in the PVN during acute stress (Evanson et al., 2010; Hill et al., 2010), which suggests that stress induces a decrease in tonic anandamide levels and evokes an increase in 2 -AG release. Here, we tested for the differential dependence on 2-AG of evoked vs tonic endocannabinoid actions in magnocellular neurons.

We first tested for the 2-AG dependence of the DSI recorded in slices from dehydrated rats with THL, an antagonist of the 2-AG synthetic enzyme diacylglycerol lipase, in identified VP-GFP and OT-RFP neurons. Bath application of THL $(10 \mu \mathrm{M})$ blocked the DSI elicited

FCA-treated slices sequentially with NO synthase and CB1 receptor blockers, in a paradigm identical to that in the previous series of experiments in slices from dehydrated rats. In the presence of the NO synthase blocker L-NAME (50 $\mu \mathrm{M})$, Dex $(1 \mu \mathrm{M})$ caused a significant $20 \%$ decrease in the mIPSC frequency in FCA-treated slices (baseline $2.0 \pm 0.4 \mathrm{~Hz}$ to $1.6 \pm 0.4 \mathrm{~Hz}$ in Dex; $p<0.05 ; n=$ 8; Fig. $5 E, F)$. The coapplication of the CB1 antagonist SR141716 $(1 \mu \mathrm{M})$ and L-NAME $(50 \mu \mathrm{M})$ completely blocked the effect of Dex on mIPSC frequency (baseline $1.6 \pm 0.2 \mathrm{~Hz}$ to $1.7 \pm 0.3 \mathrm{~Hz}$ in Dex; $p=0.76, n=4$; Fig. $5 E, F)$. Therefore, similar to our findings in slices from dehydrated rats, these results revealed a glucocorticoid-induced endocannabinoid suppression of GABA release that opposed the NO facilitation of GABA release onto SON neurons in FCA-treated slices. As confirmation of the opposing action of endocannabinoid on GABA release, when the in both VP neurons (baseline $286.9 \pm 80.3 \mathrm{pA}$ vs $277.6 \pm 72.5$ $\mathrm{pA}$ at $10 \mathrm{~s}$ postdepolarization; $p=0.72, n=7$ ) and OT neurons (baseline $417.9 \pm 86.9 \mathrm{pA}$ vs $392.2 \pm 99.1 \mathrm{pA}$ at $10 \mathrm{~s}$ postdepolarization; $p=0.10, n=4$ ) in slices from dehydrated rats (Fig. 6A). This suggested that the suppression of GABA release induced by depolarization is mediated by $2-\mathrm{AG}$ spillover onto GABA synapses in both VP and OT neurons in slices from dehydrated rats.

We next tested for the 2-AG dependence of the glucocorticoidinduced endocannabinoid suppression of GABA release in slices from dehydrated rats. In the presence of L-NAME to inhibit NO synthesis, blocking 2-AG synthesis with THL $(10 \mu \mathrm{M})$ abolished the Dex-induced decrease in mIPSC frequency (baseline $1.7 \pm 0.2 \mathrm{~Hz}$ vs $1.8 \pm 0.2 \mathrm{~Hz}$ in Dex; $p=0.72 ; n=10$; Fig. $6 B, C$ ) as well as the Dex-induced decrease in the eIPSC amplitude in magnocellular 
neurons (baseline $381.2 \pm 53.8 \mathrm{pA}$ vs $373.5 \pm 48.2 \mathrm{pA}$ in Dex; $p=0.52, n=8$; Fig. $6 C)$.

We also tested for the tonic activation of $\mathrm{CB} 1$ receptors by ambient endocannabinoids, and for the dependence of tonic $\mathrm{CB} 1$ receptor activation on (1) 2-AG synthesis and (2) glial function. The CB1 receptor antagonist SR141716 $(1 \mu \mathrm{M})$ applied alone, in the absence of an exogenous agonist, caused a $17 \%$ increase in the normalized mean frequency of mIPSCs in magnocellular neurons in slices from normally hydrated rats (baseline $2.0 \pm 0.3 \mathrm{~Hz}$ vs $2.3 \pm 0.2 \mathrm{~Hz}$ in SR141716; $p<0.05, n=$ $5)$ and a $16 \%$ increase in slices from dehydrated rats (baseline $2.3 \pm 0.3 \mathrm{~Hz}$ vs $2.6 \pm$ $0.4 \mathrm{~Hz}$ in SR141716; $p<0.05, n=6$ ). Blocking CB1 receptors with SR141716 (1 $\mu \mathrm{M})$ also caused a $17 \%$ increase in the normalized mean mIPSC frequency in FCAtreated slices from normally hydrated rats (baseline $1.7 \pm 0.2 \mathrm{~Hz}$ vs $1.9 \pm 0.3 \mathrm{~Hz} ; p<$ $0.05, n=7$; Fig. $6 D$ ). These findings with SR141716, which is also an inverse agonist at the $\mathrm{CB} 1$ receptor, were similar to our previous findings with a CB1 receptor antagonist that does not have inverse agonist activity, O-2050, in slices from normally hydrated rats, which also caused a $14 \%$ increase in the frequency of mIPSCs in magnocellular neurons (Di et al., 2009). These data revealed, therefore, an inhibitory endocannabinoid tone at GABA synapses onto magnocellular neurons that, unlike the evoked endocannabinoid actions at GABA synapses, was insensitive to the changes in glial function caused by chronic dehydration and FCA.

As shown earlier, the evoked endocannabinoid suppression of GABA input to magnocellular neurons was found to be mediated by the release of the endocannabinoid 2-AG. We next determined whether the tonic activation of $\mathrm{CB} 1$ receptors at GABA synapses on magnocellular neurons is also mediated by 2-AG. These experiments were performed in slices from both normally hydrated and dehydrated rats. Blocking 2-AG synthesis with bath application of THL $(10 \mu \mathrm{M})$ had no effect on the basal mIPSC frequency in magnocellular neurons from normally hydrated rats (baseline $2.0 \pm 0.2 \mathrm{~Hz}$ vs $1.9 \pm 0.2 \mathrm{~Hz}$ in THL; $p=$ $0.18, n=9)$. However, the subsequent addition of the CB1 receptor antagonist SR141716 $(1 \mu \mathrm{M})$ caused a 19\% increase in mIPSC frequency (baseline $1.8 \pm 0.2 \mathrm{~Hz}$ vs $2.2 \pm 0.2 \mathrm{~Hz}$ in THL $+\mathrm{SR} ; p<$ $0.05, n=5$ ), which suggested a tonic $\mathrm{CB} 1$ activation that was not dependent on 2-AG synthesis (Fig. 6E). Similarly, THL (10 $\mu \mathrm{M})$ had no effect on either the mIPSC frequency (baseline $1.7 \pm 0.1$ $\mathrm{Hz}$ vs $1.8 \pm 0.2 \mathrm{~Hz}$ in THL; $p=0.12, n=13$ ) or the eIPSC amplitude (baseline $331.9 \pm 45.1 \mathrm{pA}$ vs $342.2 \pm 43.5 \mathrm{pA}$ in THL; $p=0.41, n=11)$ in magnocellular neurons from dehydrated rats (Fig. 6E).

To control for changes in the endocannabinoid sensitivity of GABA synapses on magnocellular neurons with dehydration, we also tested the effect of exogenous 2-AG application on mIPSCs in slices from normally hydrated and chronically dehydrated rats. Bath application of 2-AG $(1 \mu \mathrm{M})$ decreased the mIPSC frequency by $23 \%$ in magnocellular neurons from normally hydrated rats (from $1.9 \pm 0.3 \mathrm{~Hz}$ to $1.5 \pm 0.2 \mathrm{~Hz} ; p<0.01, n=8$ ) and by $27 \%$ in magnocellular neurons from dehydrated rats (from $2.3 \pm 0.3$ $\mathrm{Hz}$ to $1.7 \pm 0.2 \mathrm{~Hz} ; p<0.01, n=11$ ). There was no significant difference in the effect of 2-AG on the mIPSC frequency between the control and dehydrated groups of magnocellular neurons ( $p=0.14$, unpaired, two-tailed Student's $t$ test), which indicated that the CB1 receptor sensitivity of GABA synapses on magnocellular neurons did not change with chronic dehydration.

\section{Tonic endocannabinoid modulation of GABA synapses following block of cannabinoid reuptake}

Blocking metabolic activity in glial cells led to synaptic spillover effects of evoked 2-AG release at GABA synapses, which suggests that glia control extracellular endocannabinoid levels, at least in part, via a mechanism dependent on glial metabolic function. Tonic endocannabinoid suppression of GABA release, on the other hand, was insensitive to manipulation of glial function. We next tested for endocannabinoid spillover onto GABA synapses 
A
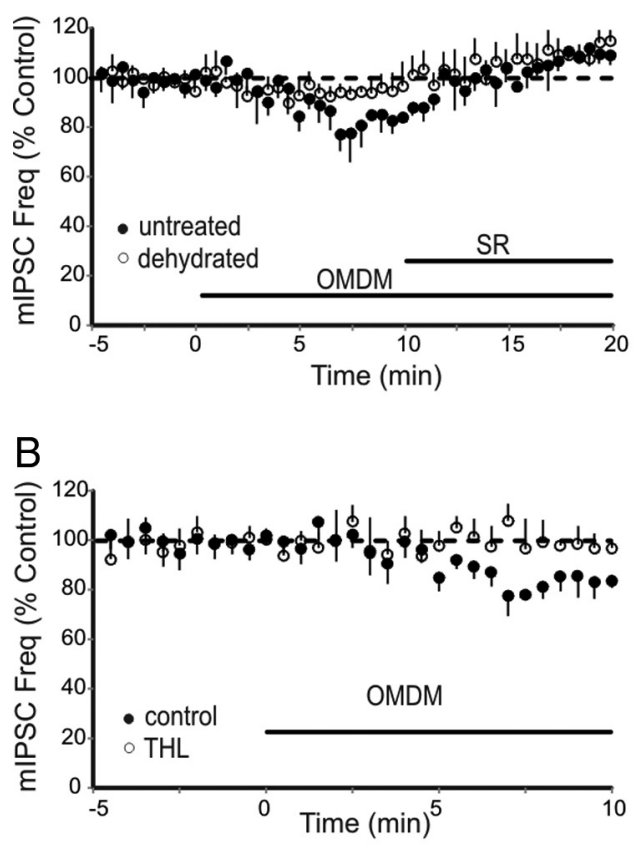

Untreated Dehydrated
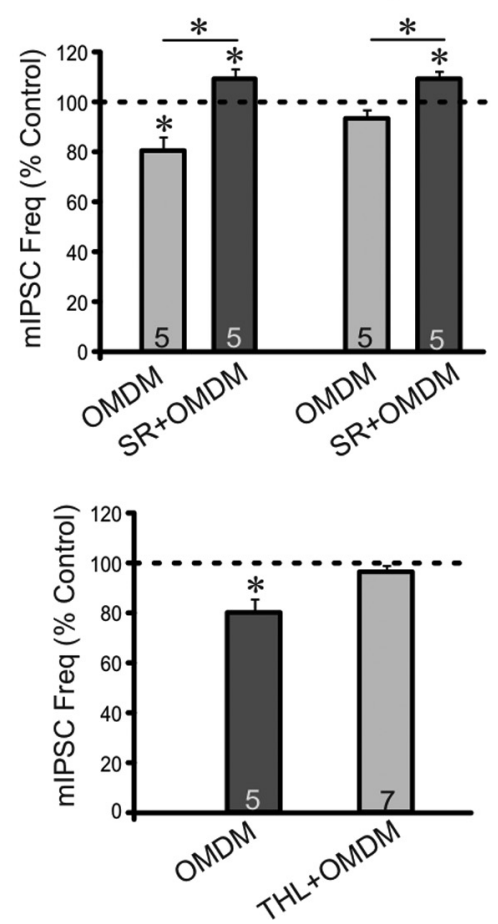

Figure 7. Inhibition of cannabinoid reuptake causes spillover 2-AG suppression of GABA release. A, Blocking endocannabinoid reuptake with the transporter blocker OMDM-2 (OMDM) caused a decrease in mIPSCs frequency, which was blocked by the (B1 receptor antagonist SR141716 (SR + OMDM) in SON neurons from normally hydrated rats. In SON neurons from dehydrated rats, blocking endocannabinoid reuptake (OMDM) had no effect on mIPSC frequency, and subsequent blockade of (B1 receptors caused an increase in mIPSC frequency (SR + OMDM). $\boldsymbol{B}$, The decrease in mIPSC frequency caused by blocking endocannabinoid reuptake (OMDM) was inhibited by blocking 2-AG synthesis with THL (THL $+0 \mathrm{MDM}) ;{ }^{*} p<0.05$.

resulting from increased endocannabinoid levels during blockade of endocannabinoid reuptake. We pharmacologically blocked endocannabinoid uptake in slices from normally hydrated and dehydrated rats with the cannabinoid transporter inhibitor OMDM-2. OMDM-2 has been reported to block endocannabinoid uptake with a $\mathrm{Ki}$ of $3 \mu \mathrm{M}$, whereas it blocks the anandamide degradative enzyme fatty acid amide hydrolase with a Ki > $50 \mu \mathrm{M}$ (Ortar et al., 2003). We used an OMDM-2 concentration of $5 \mu \mathrm{M}$ in an attempt to selectively target endocannabinoid uptake over endocannabinoid hydrolysis. OMDM-2 application in slices from normally hydrated rats caused a significant decrease in MIPSC frequency (to $81 \%$ of baseline; from $1.8 \pm 0.4 \mathrm{~Hz}$ to $1.5 \pm 0.4 \mathrm{~Hz} ; p<0.05, n=5$; Fig. $7 A$ ). Subsequent blockade of CB1 receptors with SR141716 (1 $\mu \mathrm{M})$ in slices from normally hydrated rats reversed the inhibitory effect of OMDM-2, and caused a significant increase in the frequency of mIPSCs (to $110 \%$ of baseline, from $1.8 \pm 0.3 \mathrm{~Hz}$ to $2.0 \pm 0.4 \mathrm{~Hz}$; $p<0.05, n=5$ ), which indicated that the blockade of cannabinoid transport caused an increase in extracellular endocannabinoid levels and tonic activation of $\mathrm{CB} 1$ receptors at GABA synapses. Blocking endocannabinoid reuptake with OMDM-2 in slices from dehydrated rats was without effect (baseline $2.2 \pm 0.3$ $\mathrm{Hz}$ vs $2.1 \pm 0.3 \mathrm{~Hz}$ in OMDM-2; $p=0.24, n=5$ ), whereas subsequent blockade of CB1 receptors with SR141716 (1 $\mu \mathrm{M})$ caused a significant increase in the frequency of mIPSCs (to $110 \%$ of baseline; from $2.2 \pm 0.3 \mathrm{~Hz}$ to $2.4 \pm 0.3 \mathrm{~Hz} ; p<0.05 ; n=5$; Fig. $7 A$ ), revealing an endocannabinoid inhibitory tone on the GABA synapses that was not caused by OMDM-2 blockade of endocannabinoid reuptake. Interestingly, the effect of inhibiting

endocannabinoid reuptake with OMDM-2 in slices from untreated rats was blocked by blocking 2-AG synthesis with THL (Fig. 7B), suggesting that the endocannabinoid increased by blocking endocannabinoid reuptake was 2-AG.

\section{Discussion}

We present findings from brain-slice electrophysiological experiments that strongly implicate astrocytes in the regulation of the extracellular spatial domain of retrogradely released endocannabinoids, because manipulations that reduce astrocytic buffering mechanisms caused an apparent spillover of both depolarization- and glucocorticoidinduced endocannabinoids onto GABA synapses in both magnocellular oxytocin and vasopressin neurons. Thus, under conditions of attenuated glial coverage/function, glucocorticoid- and depolarization-induced retrograde endocannabinoid release led to the suppression of synaptic transmission at GABA synapses, which was not seen under normal conditions. In contrast, tonic endocannabinoid suppression of GABA release was not affected by manipulation of glial function.

The lack of evoked endocannabinoid modulation of GABA synapses under normal conditions and its emergence following glial retraction or inhibition of glial metabolism suggest that stimulated endocannabinoid synthesis occurs at a distance from the GABA synapses and that the endocannabinoid accesses CB1 receptors at GABA synapses with the loss of glial function. This is in stark contrast to depolarization- and glucocorticoid-induced endocannabinoid actions at glutamate synapses (Di et al., 2003, 2005a,b; Hirasawa et al., 2004), and was supported by experiments in which an increase in the extracellular viscosity, and the attendant decrease in the diffusion rate, prevented the endocannabinoid suppression of synaptic GABA release in slices from dehydrated rats and in slices treated with FCA, suggesting an endocannabinoid source that is distal to the GABA synapses. Together, these findings demonstrate, therefore, (1) that the restriction of the endocannabinoid actions to glutamate synapses on magnocellular neuroendocrine cells is dependent on astrocytes; and (2) that attenuation of glial buffering leads to spillover effects of endocannabinoid onto GABA synapses. Thus, the neuronal-glial structural plasticity in the magnocellular neuroendocrine system causes retrograde endocannabinoid heterosynaptic crosstalk between glutamate and GABA synapses.

We found that both glial retraction and glial metabolic inactivation led to endocannabinoid effects on GABA synapses. We also found that decreasing endocannabinoid uptake with a transporter inhibitor led to endocannabinoid effects and increasing extracellular viscosity with dextran blocked the endocannabinoid effects at GABA synapses. Withdrawal of glial processes with dehydration should remove both the diffusion-barrier and the endocannabinoid-reuptake functions of astrocytes, whereas FCA should preferentially suppress the 
reuptake function. If we assume that FCA pretreatment of slices does not alter the morphology of astrocytes (Paulsen et al., 1987), the fact that dehydration and FCA blockade of glial metabolism both caused similar modulation of GABA synapses by evoked endocannabinoid release suggests that the glial control of extracellular endocannabinoid levels may be mediated largely by the reuptake, rather than the physical barrier, function of astrocytes; it also suggests that neuronal endocannabinoid reuptake plays a minor role in endocannabinoid buffering.

Previous reports described a tonic presynaptic suppression of GABA release onto magnocellular neurons by basal endocannabinoid actions under normal conditions (Oliet et al., 2007; Di et al., 2009; Wang and Armstrong, 2012), which seem to contradict our current observations of GABA synapse modulation by endocannabinoid only under conditions of diminished glial buffering capacity. Here, we found that both the depolarization- and the glucocorticoid-evoked endocannabinoid suppression of GABA release under conditions of glial retraction/inactivation was blocked by the DAGL inhibitor THL, indicating that it is dependent on 2-AG synthesis, whereas the tonic $\mathrm{CB} 1$ receptor-dependent modulation of GABA synapses was insensitive to DAGL inhibition. Also, we found that the tonic endocannabinoid suppression of GABA release was not affected by our glial manipulations. These findings suggest that phasic $\mathrm{CB} 1$ receptor modulation of GABA release is evoked by the stimulation of $2-A G$ release and is subject to regulation by glial buffering of extracellular endocannabinoid levels, and that tonic $\mathrm{CB} 1$ receptor activation at GABA synapses is mediated by basal anandamide release and is not regulated by glial reuptake mechanisms. Interestingly, blockade of endocannabinoid reuptake with OMDM-2 resulted in a THL-sensitive tonic $\mathrm{CB} 1$ receptor activation, which suggests that, in addition to its phasic release, $2-A G$ is also tonically released, but that basal 2-AG does not reach the CB1 receptors on GABA synapses because of glial reuptake. Because both 2-AG and anandamide are presumed to be acting at $\mathrm{CB} 1$ receptors, our findings suggest, therefore, that there are spatially distinct pools of the synthetic precursors to 2-AG and anandamide in the postsynaptic membrane and/or distinct loci of their respective target $\mathrm{CB} 1$ receptors at GABA synapses, and that the phasic and tonic 2-AG access to those receptors is controlled by the glial coverage of synapses, but the tonic CB1 receptor activation by anandamide is not. Our observations are consistent with the recent report of a differential dependence of tonic and phasic endocannabinoid synthesis at hippocampal GABA synapses on neuroligin-3, suggesting a distinct synaptic spatial organization of the two endocannabinoid synthetic machineries (Földy et al., 2013).

Astrocytes have been reported to express components of the endocannabinoid signaling system and to produce anandamide and 2-AG (Walter and Stella, 2003; Walter et al., 2004), as well as to modulate distant synapses via gliotransmitter release following endocannabinoid activation (Navarrete and Araque, 2010). If astrocytic endocannabinoids or cannabinoid receptors contributed to the endocannabinoid actions seen in our experiments, then diminishing the astrocytic-neuronal interactions by astrocyte retraction or astrocytic metabolic inhibition should reduce the effective concentration of endocannabinoids at GABA synapses and attenuate the endocannabinoid suppression of GABA release. Glial retraction and inactivation, however, had the opposite effect, promoting, rather than inhibiting, the stimulated endocannabinoid ac- tions at GABA synapses, and had no effect on the tonic CB1 receptor activation at GABA synapses. This suggests, therefore, that the endocannabinoids responsible for both the evoked and the tonic endocannabinoid actions on GABA release in the SON are synthesized by the magnocellular neurons and not by the glia in the SON.

Finally, the site of synthesis of endocannabinoids could shift to GABA synapses, or the location of CB1 receptors on GABA synapses could shift closer to the site of postsynaptic endocannabinoid synthesis following dehydration, which could account for the emergence of induced endocannabinoid actions on GABA release under this condition. However, this plasticity in endocannabinoid synthesis and/or CB1 receptor location is not likely to also occur with FCA treatment, such that this is an unlikely scenario to explain the emergence of endocannabinoid modulation of GABA release with the loss of glial function. Alternatively, CB1 receptor sensitivity of GABA synapses on magnocellular neurons could increase with dehydration, leading to an endocannabinoid suppression of GABA release not seen under normal conditions. However, our data also exclude this possibility, because there was no significant change in the response to $\mathrm{CB} 1$ receptor activation by the endocannabinoid 2-AG following chronic dehydration.

\section{Functional significance}

Although we used chronic dehydration here as an experimental manipulation to induce glial retraction to study the effect of the loss of glial coverage on trans-synaptic crosstalk, dehydration is a physiological stimulus that is experienced in the native environment (note: both salt loading and water deprivation have been shown to induce glial retraction in the SON; Theodosis et al., 2008; Elgot et al., 2012). Thus, endocannabinoid release in response to activity or to glucocorticoid exposure should have different effects on the outputs of OT and VP neurons depending on the physiological context in which the response is elicited. In normally hydrated conditions, evoked endocannabinoid release will target exclusively glutamate synapses to suppress synaptic excitation, leaving synaptic GABA inputs largely unaffected. We recently showed that, although it is inhibitory in OT neurons, GABA is excitatory in mature VP neurons (Haam et al., 2012). Therefore, selectively suppressing glutamate inputs should attenuate the synaptic excitation of both OT and VP neurons, but the inhibitory effect of this modulation should be more robust in OT neurons than in VP neurons due to the maintenance of the excitatory GABA inputs to the VP neurons. This implies, therefore, that the activation of the OT neuroendocrine system should be more strongly negatively regulated by stress-induced glucocorticoid feedback, for example, than the VP system. This may relate to the life-sustaining role of VP in blood volume/osmolality homeostatic regulation, compared with a less critical physiological role of oxytocin, and the need to maintain basic osmoregulatory function during the generalized mobilization of energy resources brought about by the stress response. It was also shown recently that GABA shifts from inhibitory to excitatory in magnocellular neurons during chronic dehydration (Kim et al., 2011), although this presumably occurs only in OT neurons because the GABA response is already excitatory in vasopressin neurons under normal conditions (Haam et al., 2012). Under dehydrated conditions, the coordinated reduction in the probability of release from both glutamate and GABA excitatory synapses by endocannabinoids should serve to dampen the synaptic excitation of both OT and VP 
neurons, both of which should be in a highly excitable state due to the enhanced glutamatergic, excitatory GABAergic and excitatory noradrenergic synaptic inputs induced by dehydration (Di and Tasker, 2004).

The mechanisms of synaptic integration are complex. Our findings that astrocytes dynamically regulate extracellular endocannabinoid levels and heterosynaptic crosstalk reveal an important glial contribution to the complex mechanisms responsible for the specificity and fine tuning of synaptic function to adapt to a changing environment.

\section{References}

Alger BE (2012) Endocannabinoids at the synapse a decade after the dies mirabilis (29 march 2001): what we still do not know. J Physiol 590:22032212. CrossRef Medline

Boudaba C, Linn DM, Halmos KC, Tasker JG (2003) Increased tonic activation of presynaptic metabotropic glutamate receptors in the supraoptic nucleus following chronic dehydration. J Physiol 551:815-823. CrossRef Medline

Deleuze C, Duvoid A, Hussy N (1998) Properties and glial origin of osmotic-dependent release of taurine from the rat supraoptic nucleus. J Physiol 507:463-471. CrossRef Medline

Di S, Tasker JG (2004) Dehydration-induced synaptic plasticity in magnocellular neurons of the hypothalamic supraoptic nucleus. Endocrinology 145:5141-5149. CrossRef Medline

Di S, Malcher-Lopes R, Halmos KC, Tasker JG (2003) Nongenomic glucocorticoid inhibition via endocannabinoid release in the hypothalamus: a fast feedback mechanism. J Neurosci 23:4850-4857. Medline

Di S, Boudaba C, Popescu IR, Weng FJ, Harris C, Marcheselli VL, Bazan NG, Tasker JG (2005a) Activity-dependent release and actions of endocannabinoids in the rat hypothalamic supraoptic nucleus. J Physiol 569:751760. CrossRef Medline

Di S, Malcher-Lopes R, Marcheselli VL, Bazan NG, Tasker JG (2005b) Rapid glucocorticoid-mediated endocannabinoid release and opposing regulation of glutamate and gamma-aminobutyric acid inputs to hypothalamic magnocellular neurons. Endocrinology 146:4292-4301. CrossRef Medline

Di S, Maxson MM, Franco A, Tasker JG (2009) Glucocorticoids regulate glutamate and GABA synapse-specific retrograde transmission via divergent nongenomic signaling pathways. J Neurosci 29:393-401. CrossRef Medline

Dudok B, Bokor H, Urban G, Mackie K, Watanabe M, Zimmer A, Freund TF, Acsady L, Katona I (2012) Pathway- and cell type-specific heterogeneity of synaptic endocannabinoid signaling in the somatosensory cortex. Program No. 639.10. 2012 Neuroscience Meeting Planner. Society for Neuroscience 2012

Elgot A, El Hiba O, Gamrani H (2012) Structural and neurochemical plasticity in both supraoptic and paraventricular nuclei of hypothalamus of a desert rodent meriones shawi after a severe dehydration versus opposite treatment by rehydration: GFAP and vasopressin immunohistochemical study. Neurosci Lett 515:55-60. CrossRef Medline

Evanson NK, Tasker JG, Hill MN, Hillard CJ, Herman JP (2010) Fast feedback inhibition of the HPA axis by glucocorticoids is mediated by endocannabinoid signaling. Endocrinology 151:4811-4819. CrossRef Medline

Földy C, Malenka RC, Südhof TC (2013) Autism-associated neuroligin-3 mutations commonly disrupt tonic endocannabinoid signaling. Neuron 78:498-509. CrossRef Medline

Fonnum F, Johnsen A, Hassel B (1997) Use of fluorocitrate and fluoroacetate in the study of brain metabolism. Glia 21:106-113. CrossRef Medline

Freund TF, Katona I, Piomelli D (2003) Role of endogenous cannabinoids in synaptic signaling. Physiol Rev 83:1017-1066. CrossRef Medline

Gordon GR, Baimoukhametova DV, Hewitt SA, Rajapaksha WR, Fisher TE, Bains JS (2005) Norepinephrine triggers release of glial ATP to increase postsynaptic efficacy. Nat Neurosci 8:1078-1086. CrossRef Medline

Gordon GR, Iremonger KJ, Kantevari S, Ellis-Davies GC, MacVicar BA, Bains JS (2009) Astrocyte-mediated distributed plasticity at hypothalamic glutamate synapses. Neuron 64:391-403. CrossRef Medline

Haam J, Popescu IR, Morton LA, Halmos KC, Teruyama R, Ueta Y, Tasker JG
(2012) GABA is excitatory in adult vasopressinergic neuroendocrine cells. J Neurosci 32:572-582. CrossRef Medline

Heifets BD, Castillo PE (2009) Endocannabinoid signaling and long-term synaptic plasticity. Annu Rev Physiol 71:283-306. CrossRef Medline

Hill MN, McLaughlin RJ, Bingham B, Shrestha L, Lee TT, Gray JM, Hillard CJ, Gorzalka BB, Viau V (2010) Endogenous cannabinoid signaling is essential for stress adaptation. Proc Natl Acad Sci U S A 107:9406-9411. CrossRef Medline

Hirasawa M, Schwab Y, Natah S, Hillard CJ, Mackie K, Sharkey KA, Pittman QJ (2004) Dendritically released transmitters cooperate via autocrine and retrograde actions to inhibit afferent excitation in rat brain. J Physiol 559:611-624. CrossRef Medline

Katoh A, Fujihara H, Ohbuchi T, Onaka T, Hashimoto T, Kawata M, Suzuki H, Ueta Y (2011) Highly visible expression of an oxytocin-monomeric red fluorescent protein 1 fusion gene in the hypothalamus and posterior pituitary of transgenic rats. Endocrinology 152:2768-2774. CrossRef Medline

Katona I, Freund TF (2012) Multiple functions of endocannabinoid signaling in the brain. Annu Rev Neurosci 35:529-558. CrossRef Medline

Katona I, Urbán GM, Wallace M, Ledent C, Jung KM, Piomelli D, Mackie K, Freund TF (2006) Molecular composition of the endocannabinoid system at glutamatergic synapses. J Neurosci 26:5628-5637. CrossRef Medline

Kim J, Alger BE (2010) Reduction in endocannabinoid tone is a homeostatic mechanism for specific inhibitory synapses. Nat Neurosci 13:592-600. CrossRef Medline

Kim JS, Kim WB, Kim YB, Lee Y, Kim YS, Shen FY, Lee SW, Park D, Choi HJ, Hur J, Park JJ, Han HC, Colwell CS, Cho YW, Kim YI (2011) Chronic hyperosmotic stress converts GABAergic inhibition into excitation in vasopressin and oxytocin neurons in the rat. J Neurosci 31:13312-13322. CrossRef Medline

Malcher-Lopes R, Di S, Marcheselli VS, Weng FJ, Stuart CT, Bazan NG, Tasker JG (2006) Opposing crosstalk between leptin and glucocorticoids rapidly modulates synaptic excitation via endocannabinoid release. J Neurosci 26:6643-6650. CrossRef Medline

McDonald NA, Kuzmiski JB, Naderi N, Schwab Y, Pittman QJ (2008) Endogenous modulators of synaptic transmission: cannabinoid regulation in the supraoptic nucleus. Prog Brain Res 170:129-136. CrossRef Medline

Min MY, Rusakov DA, Kullmann DM (1998) Activation of AMPA, kainate, and metabotropic receptors at hippocampal mossy fiber synapses: role of glutamate diffusion. Neuron 21:561-570. CrossRef Medline

Miyata S, Nakashima T, Kiyohara T (1994) Structural dynamics of neural plasticity in the supraoptic nucleus of the rat hypothalamus during dehydration and rehydration. Brain Res Bull 34:169-175. CrossRef Medline

Navarrete M, Araque A (2010) Endocannabinoids potentiate synaptic transmission through stimulation of astrocytes. Neuron 68:113-126. CrossRef Medline

Nielsen TA, DiGregorio DA, Silver RA (2004) Modulation of glutamate mobility reveals the mechanism underlying slow-rising AMPAR EPSCs and the diffusion coefficient in the synaptic cleft. Neuron 42:757-771. CrossRef Medline

Oliet SH, Piet R, Poulain DA (2001) Control of glutamate clearance and synaptic efficacy by glial coverage of neurons. Science 292:923-926. CrossRef Medline

Oliet SH, Baimoukhametova DV, Piet R, Bains JS (2007) Retrograde regulation of GABA transmission by the tonic release of oxytocin and endocannabinoids governs postsynaptic firing. J Neurosci 27:1325-1333. CrossRef Medline

Ortar G, Ligresti A, De Petrocellis L, Morera E, Di Marzo V (2003) Novel selective and metabolically stable inhibitors of anandamide cellular uptake. Biochem Pharmacol 65:1473-1481. CrossRef Medline

Paulsen RE, Contestabile A, Villani L, Fonnum F (1987) An in vivo model for studying function of brain tissue temporarily devoid of glial cell metabolism: the use of fluorocitrate. J Neurochem 48:1377-1385. CrossRef Medline

Perrais D, Ropert N (2000) Altering the concentration of GABA in the synaptic cleft potentiates miniature IPSCs in rat occipital cortex. Eur J Neurosci 12:400-404. CrossRef Medline

Piet R, Vargová L, Syková E, Poulain DA, Oliet SH (2004) Physiological contribution of the astrocytic environment of neurons to intersynaptic crosstalk. Proc Natl Acad Sci U S A 101:2151-2155. CrossRef Medline 
Tasker JG, Oliet SH, Bains JS, Brown CH, Stern JE (2012) Glial regulation of neuronal function: from synapse to systems physiology. J Neuroendocrinol 24:566-576. CrossRef Medline

Theodosis DT, Poulain DA (1999) Contribution of astrocytes to activitydependent structural plasticity in the adult brain. Adv Exp Med Biol 468:175-182. CrossRef Medline

Theodosis DT, Poulain DA, Oliet SH (2008) Activity-dependent structural and functional plasticity of astrocyte-neuron interactions. Physiol Rev 88:983-1008. CrossRef Medline

Ueta Y, Fujihara H, Serino R, Dayanithi G, Ozawa H, Matsuda K, Kawata M, Yamada J, Ueno S, Fukuda A, Murphy D (2005) Transgenic expression of enhanced green fluorescent protein enables direct visualization for physiological studies of vasopressin neurons and isolated nerve terminals of the rat. Endocrinology 146:406-413. CrossRef Medline
Walter L, Stella N (2003) Endothelin-1 increases 2-arachidonoyl glycerol (2-AG) production in astrocytes. Glia 44:85-90. CrossRef Medline

Walter L, Dinh T, Stella N (2004) ATP induces a rapid and pronounced increase in 2-arachidonoylglycerol production by astrocytes, a response limited by monoacylglycerol lipase. J Neurosci 24:8068-8074. CrossRef Medline

Wang L, Armstrong WE (2012) Tonic regulation of GABAergic synaptic activity on vasopressin neurones by cannabinoids. J Neuroendocrinol 24:664-673. CrossRef Medline

Wilson RI, Nicoll RA (2002) Endocannabinoid signaling in the brain. Science 296:678-682. CrossRef Medline

Yoshida T, Uchigashima M, Yamasaki M, Katona I, Yamazaki M, Sakimura K, Kano M, Yoshioka M, Watanabe M (2011) Unique inhibitory synapse with particularly rich endocannabinoid signaling machinery on pyramidal neurons in basal amygdaloid nucleus. Proc Natl Acad Sci U SA 108: 3059-3064. CrossRef Medline 